\title{
(CON/DI)VERGÊNCIAS DAS ÁREAS \\ DE CONHECIMENTO NA PEDAGOGIA \\ UNIVERSITÁRIA DAS LICENCIATURAS
}

(CON/DI)VERGENCES OF THE AREAS OF KNOWLEDGE IN THE

UNIVERSITY PEDAGOGY OF LICENTIATE DEGREES

(CON/DI)VERGENCIAS DE LAS ÁREAS DE CONOCIMIENTO EN

LA PEDAGOGÍA UNIVERSITARIA DE CURSOS DE FORMACIÓN INICIAL DE PROFESORES

\author{
Luana Rosalie Stahl ${ }^{1}$ \\ Rede Estadual de Ensino, Professora de Língua Espanhola
}

Greice Scremin ${ }^{2}$

Centro Universitário Franciscano, Professora Adjunta do Programa de Pós-Graduação em Ensino de Ciências e Matemática

\section{Silvia Maria de Aguiar Isaia ${ }^{3}$}

Centro Universitário Franciscano, Professora Adjunta do Programa de Pós-Graduação em Ensino de Ciências e Matemática

\begin{abstract}
Resumo: Com este trabalho objetivou-se investigar as influências das áreas específicas de conhecimento dos professores de uma Instituição de Ensino Superior (IES) pública nos movimentos da docência universitária e discutir potenciais indicadores que caracterizam uma Pedagogia Universitária das licenciaturas nas áreas de Ciências Humanas $(\mathrm{CH})$ e Linguística, Letras e Artes (LLA). O trabalho foi realizado a partir das narrativas de 13 docentes. A pesquisa é qualitativa, de cunho narrativo (CONNELLY; CLANDININ, 1995; MCEVAN, 1998), e os achados foram submetidos à Análise Textual Discursiva (MORAES; GALIAZZI, 2007). Concluiu-se que as licenciaturas

\footnotetext{
${ }^{1}$ Mestre e doutoranda em Educação pelo Programa de Pós-Graduação em Educação da Universidade Federal de Santa Maria.

${ }^{2}$ Mestre e Doutora em Educação pelo Programa de Pós-graduação em Educação da Universidade Federal de Santa Maria.

${ }^{3}$ Doutora em Educação pela Universidade Federal do Rio Grande do Sul; Mestre em Filosofia pela Universidade Federal de Santa Maria.
} 
possuem aspectos convergentes e divergentes que evidenciam que pedagogias específicas podem ser configuradas com estratégias formativas próprias para a docência.

Palavras-chave: Pedagogia Universitária. Áreas de conhecimento. Licenciaturas.

\begin{abstract}
This study aimed to investigate the influences of the teacher's knowledge specific areas of a public Higher Education Institution (HEI) in movements of the university teaching, and to discuss potential indicators that characterize a University Pedagogy of the licentiate degrees in the areas of Human Sciences (HS) and Linguistics, Letters and Arts (LLA). The work was performed from the narratives of 13 teachers. The research was qualitative, of narrative type (CONNELLY; CLANDININ, 1995; MCEVAN, 1998), and the findings passed through a discursive textual analysis (MORAES; GALIAZZI, 2007). It was concluded that the licenciate courses have convergent and divergent aspects showing that specific pedagogies can be configured with formative strategies specific for teaching.
\end{abstract}

Keywords: University pedagogy. Knowledge areas. Licentiate courses.

Resumen: Este trabajo objetiva investigar las influencias de las áreas especificas de conocimiento de los profesores de una IES publica en los movimientos de la docencia universitaria y discutir potenciales indicadores que caracterizan una Pedagogía Universitaria de cursos de formación inicial de profesores en las áreas de Ciencias Humanas y Lingüistica, Letras y Artes. El trabajo fue realizado a partir de las narrativas de 13 docentes. La investigación es cualitativa, de carácter narrativo (CONNELLY; CLANDININ, 1995; MCEVAN, 1998) y los hallazgos fueron sometidos a la Análisis Textual Discursiva (MORAES; GALIAZZI, 2007). Se concluyó que los cursos de formación inicial de profesores poseen aspectos convergentes y divergentes que evidencian que pedagogías especificas pueden configurarse, con estrategias formativas propias para la docencia.

Palabras clave: Pedagogía Universitaria. Áreas de conocimiento. Cursos de Formación Inicial de Profesores.

\title{
1 INTRODUÇÃO
}

Neste trabalho apresentam-se e discutem-se os resultados parciais de um estudo que vem sendo realizado no contexto do Grupo Trajetórias de Formação (GTFORMA) do Conselho Nacional de Desenvolvimento científico e Tecnológico (CNPq). O objetivo foi investigar as influências das áreas específicas de conhecimen- 
to dos professores de uma Instituição de Ensino Superior (IES) pública nos movimentos da docência universitária e discutir os potenciais indicadores que caracterizam uma Pedagogia Universitária das licenciaturas nas áreas de Ciências Humanas $(\mathrm{CH})$ e Linguística, Letras e Artes (LLA). Busca-se, portanto, contribuir para as pesquisas na área da Educação Superior, explorando o campo da Pedagogia Universitária como uma possibilidade para a compreensão da atuação dos professores nesse nível de ensino. Esses objetivos vêm permeados pela necessidade de estudos que tenham como pano de fundo as especificidades das áreas de conhecimento e o saber acadêmico delas decorrentes, buscando a compreensão sobre convergências ou divergências na constituição das pedagogias próprias às licenciaturas.

Os movimentos da docência superior são compreendidos como um processo que envolve os diferentes momentos da carreira docente, bem como a trajetória vivencial dos professores e o modo como eles articulam as dimensões pessoal, profissional e institucional e, consequentemente, como vão se (trans)formando no decorrer do tempo.

A pesquisa mais ampla envolve 60 sujeitos professores de bacharelados e licenciaturas das diferentes áreas do conhecimento (pela classificação do CNPq). É importante sinalizar que se entende que as áreas específicas de conhecimento envolvem os saberes acadêmicos delas decorrentes, que precisam ser trabalhados no processo da docência. Assim, o conhecimento da área específica compreende os conhecimentos sobre o componente curricular a ser ensinado pelo professor em suas dimensões conceituais e organizacionais, além de "“[...] ideias, informações, definições, convenções e tópicos gerais, bem como sua estrutura organizacional. [...] tendências e perspectivas de seu campo específico, $[. .$.$] as diferentes interpretações de um mesmo fenômeno e suas rela-$ ções [...]” (BOLZAN, 2006, p. 357-358).

Neste artigo, realizamos um recorte no qual discutimos a respeito dos saberes decorrentes de duas áreas analisadas em uma das etapas da pesquisa (Ciências Humanas (CH) e Linguística, Letras e Artes (LLA)), em que, de acordo com os tempos de docência superior na IES, totalizam 13 sujeitos entrevistados.

A opção metodológica foi a abordagem qualitativa, de cunho narrativo, tendo como procedimento de pesquisa a entrevista narrativa. A análise dos achados foi assentada nos princípios da Análise Textual Discursiva (MORAES; GALIAZZI, 2007).

As discussões teóricas envolvidas neste trabalho abordam o conceito de Pedagogia Universitária, discutido com base em autores como Bolzan e Isaia (2010) e Cunha (2006, 2009, 2010); a definição de Movimentos da Docência Superior e as 
noções de áreas de conhecimento específicos, a partir dos estudos de Isaia e Maciel (2013), são o foco de nossa análise.

\section{TRAMAS TEÓRICAS}

A Pedagogia Universitária, como campo de estudos e produção de conhecimento sobre a docência na Educação Superior, é discutida a partir da necessidade de reflexões pautadas em demandas formativas. Estas estão assentadas na evidência da importância da construção da profissionalidade dos professores que atuam na Educação Superior, a partir das especificidades que caracterizam esses profissionais, buscando constituir um campo sólido de pesquisa e produção de conhecimentos que enfoquem o fazer pedagógico destes (CUNHA, 2009).

Considerando a inexistência de um curso de formação inicial para professores que atuam na Educação Superior, esse tema de pesquisa é polissêmico e prenhe de possibilidades investigativas. Nesse sentido, Bolzan e Isaia (2010) destacam que a Pedagogia Universitária é um campo de investigação em construção, no qual os processos de aprender e ensinar profissões são analisados e compreendidos, possibilitando novos olhares sobre a prática docente e contribuindo para a qualidade do ensino superior.

Inseridos no contexto das pesquisas sobre Pedagogia Universitária, enfocamos neste trabalho a atuação de formadores de professores de duas áreas de conhecimento e seus tempos de carreira, considerando que os indicadores apontados poderão ampliar as discussões a respeito da influência da área específica de conhecimentos nos fazeres pedagógicos próprios ao ensino na universidade.

A noção de movimentos da docência superior é relevante no contexto deste trabalho porque procuramos evidências da relação entre o tempo de docência e a influência dessa experiência na compreensão e entendimento dos professores das áreas acerca de sua atuação na formação de futuros professores. De acordo com Isaia e Maciel (2013, p. 3), os movimentos da docência apresentam idiossincrasias que consideram:

[...] as trajetórias pessoais e profissionais dos professores; o modo como, a partir das marcas dessas trajetórias, enfrentam e concebem a docência; a contextualização epistemológica das áreas específicas de conhecimento e do saber acadêmico a que estes sujeitos estão ligados; e de que maneira podem articular os diversos saberes e fazeres próprios à construção da mesma, 
evidenciando ou não a possibilidade de uma produção pedagógica.

Desse modo, o movimento investigativo empreendido neste trabalho diz respeito tanto às especificidades inerentes a cada uma das áreas de conhecimento quanto às especificidades próprias à vida do professor e sua trajetória profissional. Essas marcas advindas da experiência no campo da docência parecem sinalizar uma possibilidade de elucidação da relação entre áreas específicas e atuação docente.

Assim, compreender os movimentos da docência superior implica considerar a área específica e o saber acadêmico produzido pelo professor a partir da área na relação ensino e aprendizagem. Portanto, a base epistemológica da profissão professor se assenta na constituição dessa compreensão, ou seja, o caminho pelo qual o professor, a partir do conhecimento específico de cada área, entende, produz questionamentos e elabora respostas que são dinamizadas na ação de ensinar. Essas respostas estão ligadas à epistemologia científica, mas sofrem adaptações que as tornam passíveis de compreensão pelos estudantes.

Nesse sentido, torna-se pertinente compreender a relação que as áreas específicas de conhecimento estabelecem no modo com o qual os docentes compreendem o fazer pedagógico por eles elaborado, tendo como pano de fundo os movimentos da docência superior.

As áreas específicas do conhecimento são definidas neste trabalho a partir da classificação do CNPq: Ciências Exatas e da Terra; Ciências Biológicas; Engenharias; Ciências da Saúde; Ciências Agrárias; Ciências Sociais Aplicadas; Ciências Humanas; Linguística, Letras e Artes. Conforme destacamos anteriormente, neste trabalho trazemos apenas as Ciências Humanas $(\mathrm{CH})$ e Linguística, Letras e Artes (LLA). Assim, a análise a que nos propomos neste artigo está relacionada à formação de professores, uma vez que tem como foco investigativo duas áreas de conhecimento que, genuinamente, formam futuros profissionais que atuarão na Educação Básica.

Pesquisas realizadas pelo GTFORMA têm evidenciado que a Pedagogia Universitária está assentada no conhecimento específico da área (ISAIA; MACIEL, 2013) mesmo quando a tônica é a formação de professores (SCREMIN, 2014; STAHL, 2013), ou seja, sobre o componente curricular que este professor ensina e no campo específico de conhecimento a ele relacionado. Se a importância desses conhecimentos é incontestável para a profissão docente, também sabemos que a formação pautada na atividade docente, centrada única e exclusivamente nesta, pode acarretar consequências negativas para a formação de futuros profissionais. Na formação de 
professores, possíveis consequências são a falta de articulação entre as dimensões específica e pedagógica, a ausência de uma reflexão significativa sobre os processos de ensino e aprendizagem que explorem a realidade dos contextos educativos, a incoerência entre o que é exigido na formação inicial nas instituições de educação superior e a realidade do campo profissional, e a inexistente noção de transposição didática nos processos formativos que possibilite que os conteúdos sejam apreendidos e ensinados.

Nesse sentido, é relevante que estudos enfoquem as diferentes áreas do conhecimento e a produção da Pedagogia Universitária (FRANCO; KRAHE, 2007). Tais estudos podem auxiliar a compreensão da constituição e do modo pelo qual a Pedagogia Universitária se configura, considerando que envolve conteúdos disciplinares distintos e a transformação destes em conteúdos pedagógicos.

\section{ENCAMINHAMENTOS METODOLÓGICOS}

Em nossos estudos, temos desenvolvido a pesquisa de abordagem qualitativa de cunho narrativo (CONNELLY; CLANDININ, 1995; MCEVAN, 1998). A narrativa possibilita um revisitar a memória de situações vivenciadas no passado mais ou menos remoto. O distanciamento dessas experiências para narrá-las faz com que os sujeitos as reconstruam e as reorganizem de modo que selecionam os acontecimentos importantes e as relações significativas (MCEWAN, 1998). Considerando o grande número de sujeitos da pesquisa, foi necessário criar estratégias de análise dos dados de acordo com as características do grupo de pesquisa.

Desse modo, inicialmente, cada membro do grupo de pesquisa recebeu certo número de entrevistas para serem organizadas em quadros, sistematizando a matriz da investigação. Após essa fase, pequenos grupos foram criados a fim de analisar os quadros agrupados por áreas do conhecimento. O grupo que produziu este artigo ficou responsável por duas áreas; por essa razão, discutimos os saberes decorrentes de duas áreas analisadas nessa etapa da pesquisa (Ciências Humanas $(\mathrm{CH})$ e Linguística, Letras e Artes (LLA)).

De acordo com os tempos de docência superior na IES, os sujeitos estão assim identificados: de 0 a 5 anos, Professor Anos Iniciais (PAI); de 6 a 15 anos, Professor Anos Intermediários (PAT); e 16 anos em diante, Professor Anos Finais (PAF), totalizando 13 sujeitos oriundos das licenciaturas da IES, conforme a Tabela 1: 
Tabela 1 - Identificação dos sujeitos

\begin{tabular}{ccccc}
\hline & PAI & PAT & PAF & TOTAL \\
\hline CH & 4 & 1 & 2 & 7 \\
LLA & 2 & 3 & 1 & 6 \\
& & 13 Sujeitos & \\
Fonte: os autores. & \multicolumn{3}{l}{}
\end{tabular}

Nesse contexto, a interpretação analítica das narrativas dos professores foi realizada por meio da Análise Textual Discursiva (MORAES; GALIAZZI, 2007). Esse tipo de análise exige constantemente a (re)construção de caminhos. Esses autores apresentam quatro pontos que compõem a análise discursiva e que estão divididos em dois ciclos diferentes. As três primeiras fases: desmontagem dos textos, estabelecimento de relações e captando o novo emergente constituem o primeiro ciclo, e o último é o ciclo como um todo, pois aproxima sistemas complexos em um processo auto-organizado.

Portanto, a dinâmica interpretativa ocorre em ciclos. No primeiro ciclo, então, temos a primeira fase que corresponde à desmontagem dos textos (processo de unitarização), que se caracteriza pela análise e fragmentação em unidades constituintes do fenômeno estudado; a segunda fase, o estabelecimento de relações, é um processo de categorização resultado da classificação e combinação das unidades de base anteriormente unitarizadas; a terceira e última fase do primeiro ciclo, captando o novo emergente, é a emergência de uma nova compreensão, bem como da consciência de validação e crítica do fenômeno estudado. O ciclo seguinte, o processo auto-organizado, sinaliza os resultados finais, que são criativos e originais e não haviam sido previstos.

As narrativas são compreendidas como materiais textuais, por isso são objetos de estudo do pesquisador, que atribui sentido e significado a eles. Nessa perspectiva, de acordo com Moraes e Galiazzi (2007), a análise textual discursiva das entrevistas narrativas transcritas é um conjunto de significantes que receberá significado após a análise do pesquisador e a partir da escrita resultante da compreensão do processo.

Com base na noção de ciclos proposta por Moraes e Galiazzi (2007), algumas estratégias foram assumidas para a Análise Textual Discursiva das entrevistas. A primeira estratégia utilizada foi projetar cada quadro de entrevista em uma tela para que todos os membros do grupo pudessem visualizar e discutir a respeito dos indicadores por área de conhecimento de cada sujeito. Feito isso, passou-se para uma 
segunda etapa, na qual se projetou um quadro com as inferências encontradas por área, separando as considerações dos sujeitos por tempo de docência. Em um terceiro momento, viu-se a necessidade de compilar as inferências por área, cruzando-as com o tempo de docência. A partir daí, nossas conclusões foram tornando-se interessantes porque possibilitaram que encontrássemos as convergências e as divergências por área e por tempo de docência, concomitantemente, caracterizando, assim, as análises e as conclusões neste trabalho.

\section{ANÁLISE E DISCUSSÃO DOS RESULTADOS}

A Matriz Categorial da Investigação que orientou a realização das entrevistas narrativas foi subdividida em três grandes eixos, compostos por indicadores sobre os quais os docentes foram indagados nas entrevistas narrativas.

Esquema 1 - Matriz Categorial da Investigação



Fonte: os autores. 
Descrevemos os indicadores que compõem cada um desses eixos, tendo como pontos balizadores as áreas e o tempo de carreira docente, e, na sequência, evidenciamos pontos divergentes e convergentes.

\subsection{EIXO 1 - ÁREA DO CONHECIMENTO ESPECÍFICO}

Busca identificar o modo como os sujeitos compreendem, definem e relacionam a sua área de conhecimento específico. Os indicadores que delimitam esse eixo são:

a) Definição pessoal da área de conhecimento específico;

Linguística, Letras e Artes (LLA): os Professores dos Anos Iniciais (PAI) dessa área apresentaram dificuldades para definir a área específica, demonstrando certo conflito entre a área do concurso que realizaram e a trajetória formativa. Nesse sentido, há disparidades entre as definições da área específica, pois esta pode ser bastante ampla (a grande área) ou, especificamente, a área de atuação baseada no concurso. Os Professores dos Anos Intermediários (PAT) demonstram consciência da delimitação do conhecimento específico, e os Professores dos Anos Finais (PAF) definem o conhecimento específico a partir da formação inicial, pesquisa e pós-graduação.

Ciências Humanas (CH): os PAI e os PAT não demonstraram clareza quanto à definição da área específica do conhecimento. Para os PAF, a definição do conhecimento específico ocorreu por meio das atribuições que o profissional da área específica tem.

b) Conhecimentos básicos da sua área;

Linguística, Letras e Artes (LLA): sobre os conhecimentos básicos da sua área, os PAI consideram os conhecimentos ligados ao componente curricular que lecionam, o que converge com sua definição do conhecimento específico. Os PAT não mencionam com clareza as definições relativas aos conhecimentos básicos. Por sua vez, os PAF destacam que os conhecimentos básicos estão balizados pelos conhecimentos da área específica.

Ciências Humanas $(\mathrm{CH})$ : os PAI e os PAT não mencionam com clareza essas definições relativas aos conhecimentos básicos. Nos PAF aparece a noção dialógica entre conhecimentos práticos e teóricos, entretanto, centrados no conhecimento específico. A explicitação dos conhecimentos básicos demonstra que os professores enfatizam o conhecimento da área específica (seja ela definida pela formação inicial, pelas áreas de pesquisa ou pela pós-graduação). 
c) Inter-relações conceituais e com áreas afins.

Linguística, Letras e Artes (LLA): as inter-relações são evidenciadas pelos PAI como relacionadas a áreas afins que dialogam entre si e com a área específica. Os PAT demonstram clareza com o que consideram inter-relações conceituais, entretanto, estas aparecem nas entrevistas sempre relacionadas às áreas correlatas. Os PAF explicitam as inter-relações conceituais, entretanto, quando ocorrem, parecem estar muito mais relacionadas às áreas. Quando os professores apresentaram conceitos, não exemplificaram de que modo essas relações ocorrem na prática docente, mas reconheceram e exemplificaram a relevância das articulações com outras áreas de conhecimento, inclusive para compreender a área específica.

Ciências Humanas (CH): Os PAI não demonstraram clareza sobre esse indicador. Os PAT demonstram clareza com o que consideraram inter-relações conceituais, entretanto estas aparecem nas entrevistas sempre relacionadas às áreas correlatas. Os PAF trataram as inter-relações conceituais a partir da definição de conhecimento da área específica e dos conhecimentos básicos apresentados. A noção de inter-relação conceitual está presente na grande maioria das entrevistas com PAF, no entanto a clareza e a explicitação dos conceitos parece estar atrelada às áreas que se inter-relacionam. As inter-relações são explicadas de modo claro, tendo como fio condutor o diálogo das áreas com a área específica (formação específica). Assim como nos conceitos, no que se refere às áreas afins, a justificativa está na área específica, demonstrando uma centração significativa no campo da área de conhecimento específico.

\subsection{EIXO 2 - ARTICULAÇÃO DO CONHECIMENTO ESPECÍFICO E SABER ACADÊMICO}

Esse eixo tem a intenção de identificar se os docentes têm consciência dos distintos modos como o conhecimento específico (decorrente de um campo científico) pode ser reorganizado em outros níveis para a aprendizagem dos estudantes. Os indicadores que compõem esse eixo são:

a) Diferenciação entre o conhecimento específico da área e o saber acadêmico trabalhado em aula;

Linguística, Letras e Artes (LLA): os PAI fazem diferenciação ao reconhecerem que para dar aula existem elementos que devem ser considerados, como a linguagem, a adequação do material, a preocupação não somente com o conteúdo, mas em como trabalhar visando à aprendizagem de seus acadêmicos. No entanto, esses do- 
centes não expõem claramente as diferenças entre os conhecimentos específicos e os saberes acadêmicos, ainda que reconheçam a importância e a função da metodologia utilizada pelo professor para a aprendizagem de seus alunos. Sobre os PAT, é possível constatar que a área específica de conhecimento não influencia a diferenciação entre conhecimento específico da área e o saber acadêmico. Verificamos, entretanto, que há professores que, além de diferenciarem, trazem a noção de transposição didática, explicitando a forma como organizam os conteúdos disciplinares nas propostas de ensino em sala de aula, evidenciando as noções de níveis de compreensão a partir do conhecimento do campo científico. Para os PAF, há divergências bem importantes na compreensão da diferenciação do conhecimento específico e do saber acadêmico. Todos os professores entendem que há uma diferenciação, no entanto, o nível de consciência desta se apresenta de, pelo menos, duas maneiras distintas: aqueles que não definem o saber acadêmico, mas demonstram consciência no que diz respeito à diferenciação entre conhecimento específico e saber acadêmico, e aqueles que explicitam de modo mais claro a diferenciação, apontando que o saber acadêmico é dinâmico, e, por isso, cabe ao professor trabalhar o conhecimento específico na sala universitária de modo que o estudante compreenda essa dinâmica e saiba onde buscar outros subsídios para aprofundamento dessa compreensão.

Ciências Humanas $(\mathrm{CH})$ : os PAI não evidenciam clareza sobre essa diferenciação. Nas narrativas dos PAT identificamos diferenciação a partir das noções de teoria e prática, justificando que não é possível trabalhá-las separadamente. Os PAF apresentam clareza na diferenciação entre conhecimento específico da área e saber acadêmico trabalhado em sala de aula, no entanto ela fica no nível das adequações na linguagem. Não há uma diferenciação explícita no campo dos conhecimentos, mas a compreensão que os projetos de extensão complementam o saber acadêmico, subsidiando suporte prático aos conhecimentos específicos. Essa compreensão explicitada pelos docentes evidencia uma maneira de transpor didaticamente esses conhecimentos para outros níveis de ensino que não aquele no qual atua como formador. Inferimos que, em geral, os projetos de extensão citados pelos entrevistados articulam a universidade com a escola, possibilitando que o conhecimento específico seja mobilizado nesse contexto e exigindo que haja a noção de adaptação.

b) Articulação entre o conhecimento específico e o conhecimento acadêmico trabalhado em aula.

Linguística, Letras e Artes (LLA): os PAI reconhecem a especificidade de cada contexto e mencionam que realizam essa articulação, mas não demonstram como. Os PAT consideraram que a articulação ocorre a partir dos conhecimentos tra- 
zidos pelos alunos (conhecimento prévio) para que sejam desenvolvidas as discussões em sala de aula universitária. Assim, o saber acadêmico é trabalhado na sala de aula a partir dos conhecimentos prévios dos alunos. Nas falas dos PAF, a articulação é explicitada a partir das explicações nutridas pela formação na pós-graduação e trazidas para a linguagem do meio acadêmico. Outro elemento presente nas narrativas e que perpassa a noção do tempo de docência é a questão das relações interpessoais no processo ensino-aprendizagem, indicando que implicam o modo de condução do processo de compreensão do aluno.

Ciências Humanas $(\mathrm{CH})$ : os PAI não explicitaram como fazem as articulações; já os PAT reconheceram a articulação do conhecimento específico e do saber acadêmico, no entanto projetaram a responsabilidade dessa articulação para seus alunos. Para os PAF, a articulação está fundada nas noções de diferenciação e transposição didática, sustentadas pela experiência profissional e pelas inter-relações pessoais com os sujeitos da aprendizagem.

\subsection{EIXO 3 - ÁREA DO SABER ACADÊMICO EM AÇÃO}

Esse eixo busca evidenciar o modo com o qual os docentes organizam sua prática cotidiana e como entendem que a sua atuação contribui na formação dos estudantes. Os indicadores que caracterizam esse eixo são:

a) Clareza quanto aos conhecimentos da área específica que são importantes para o processo formativo do estudante;

Linguística, Letras e Artes (LLA): os PAI reconhecem que para dar aula existem saberes que devem ser considerados, como a linguagem, a adequação do material, a preocupação não somente com o conteúdo, mas em como trabalhar esse conteúdo visando à aprendizagem de seus acadêmicos. Os PAT demonstram clareza em relação aos conhecimentos específicos da área que são trabalhados nos componente curriculares teóricos que ministram e que perpassam a formação do estudante da área. Os PAF destacaram que o conhecimento específico é o carro chefe da noção de processo formativo. Nem sempre a noção de formação está vinculada à prática do estudante, mas existe uma preocupação no sentido de articular noções teóricas e práticas na formação do estudante.

Ciências Humanas ( $\mathrm{CH})$ : os PAI não evidenciaram clareza sobre esse indicador, e os PAT não compreenderam a pergunta. Os PAF evidenciaram que a clareza dos conhecimentos está atrelada, primeiramente, aos conhecimentos específicos da 
área, buscando uma compreensão que parte do todo para trabalhar as partes. Nesse sentido, as noções gerais do conhecimento específico são trabalhadas primeiramente para que possam ser trabalhadas as especificidades e particularidades relacionadas aos cursos nos quais trabalham e o conhecimento específico da área (o conhecimento pedagógico aparece como algo a ser acrescentado na formação quando o estudante é de licenciatura, buscando links entre conhecimentos específicos e pedagógicos). Destaca-se a centração nos conhecimentos específicos, ainda que haja a compreensão da necessidade do trabalho que articule conhecimentos teóricos e práticos. A clareza dos conhecimentos é determinada pelo curso de formação no qual atuam.

Esse indicador demonstra que para os sujeitos da área LLA há uma centralização dos conhecimentos específicos da área, e nos sujeitos da área $\mathrm{CH}$ é possível observar que a preocupação é mais ampla em relação aos conhecimentos que o estudante necessita.

Nesse sentido, a percepção dos professores sobre os conhecimentos que são importantes para o processo formativo do estudante está intimamente relacionada ao perfil profissional desejado para a formação na área, contemplando os saberes da área específica, bem como saberes mais amplos da profissão docente.

b) Aplicabilidade desse conhecimento articulado no mundo do trabalho;

Linguística, Letras e Artes (LLA): os PAI apresentam dificuldades em fazer a transposição do saber acadêmico para o mundo do trabalho, além de problemas na dinâmica curricular em relação aos estágios, que se encontram mais no final do curso. Tentam articular a teoria e a prática. Para os PAT, a articulação com o mundo do trabalho ocorre pela compreensão de que não deve haver uma lacuna/fronteira entre o conhecimento específico trabalhado em aula e os conhecimentos prévios e de senso comum que os alunos trazem consigo. Os PAF buscam a aplicabilidade por meio de exemplos de profissionais e projetos que viabilizem a inserção do estudante na realidade profissional; há clareza quanto ao campo profissional.

Ciências Humanas $(\mathrm{CH})$ : os PAI não evidenciaram a compreensão da aplicabilidade. Os PAT explicitam a ideia de profissional que a escola precisa e que tipo de profissional a universidade está formando para o campo específico da área. Os PAF explicitam a necessidade de conexões constantes entre o conhecimento trabalhado na sala de aula e o campo profissional no qual o estudante atuará. A licenciatura aparece como exemplo do distanciamento ainda existente entre formação de professores e escola, destacando-se a necessária e constante busca de articulações desses espaços. As especificidades dos cursos parecem "formatar" o olhar que o docente tem para o mundo do trabalho que o seu estudante "enfrentará". 
No que se refere a esse indicador, para os sujeitos da área $\mathrm{CH}$, parece que há maior preocupação com a aplicabilidade do conhecimento no campo da escola (licenciatura). Já para os sujeitos da área LLA, apesar de os cursos analisados formarem professores, não há essa clareza nas falas. Outro aspecto relevante é que os Professores em Anos Iniciais de Docência (PAI) enfrentam maiores desafios na abordagem do campo profissional, talvez por conta da característica da profissão docente universitária e das demandas da atualidade quanto à formação em nível de pós-graduação stricto sensu. Tais fatores contribuem para que os professores universitários sejam recém-doutores, sem experiência no campo profissional e com dedicação exclusiva à instituição, o que contribui para o distanciamento do mercado de trabalho da profissão.

c) Forma de organizar o conhecimento acadêmico para a compreensão do aluno;

Linguística, Letras e Artes (LLA): para os PAI, o professor se remete à vivência da sua formação inicial e vai desenvolvendo atividades que acredita serem pertinentes no processo formativo na atualidade. Assim, vai "tateando" a partir de suas experiências, bem como as reproduzindo. Utiliza algumas estratégias pedagógicas que vêm sendo reproduzidas ao longo dos anos. Para os PAT, o foco está nas necessidades do acadêmico; há todo um movimento para entender o processo de criação, produção e elaboração dos alunos. Há também referência à articulação ensino-pesquisa-extensão que tende a organizar o processo didático para o ensino dos conteúdos da área específica. Em PAF, a articulação de conhecimentos é apontada como ferramenta para a compreensão dos alunos; a articulação entre pesquisa, extensão e ensino aparece como modo de sistematização e articulação.

Ciências Humanas $(\mathrm{CH})$ : os PAI não explicitam. Os PAT apresentam a noção de níveis de aprofundamento diferentes, do simples para o complexo. Os PAF explicitam noções claras de diferenciação e dinâmicas organizativas do conhecimento, incluindo noções de transposição didática (adequação linguística, diferenciação dos conhecimentos). De diferentes modos, a noção de transposição didática parece emergir nas práticas docentes.

A respeito desse indicador, a aplicabilidade fica mais evidenciada em sujeitos da área $\mathrm{CH}$; já em sujeitos da área LLA, há menção à tríade pesquisa, ensino e extensão. Nesse sentido, há divergência sobre o entendimento das formas de organização dos conhecimentos, mas há convergência no objetivo final das aprendizagens.

d) Estratégias utilizadas para a compreensão;

Linguística, Letras e Artes (LLA): aos PAI, há clareza em relação aos diferentes instrumentos e estratégias. Utilizam algumas estratégias pedagógicas que vêm 
sendo reproduzidas ao longo dos anos. Os PAT buscam constantemente mecanismos e métodos que possibilitam tanto a prática quanto a teoria (mesclar), além de instigar/ problematizar a capacidade de resolver problemas em diferentes situações e contextos fora da universidade, já no mercado de trabalho. Os PAF utilizam diferentes estratégias, que são dinamizadas a partir das necessidades do conteúdo/conhecimento, buscando a compreensão a partir da relação entre teoria e prática. A relação entre professor e aluno também aparece como importante ferramenta na construção das estratégias utilizadas na prática docente.

Ciências Humanas $(\mathrm{CH})$ : os PAI e os PAT não explicitam. Para os PAF, a dimensão da relação professor-aluno está fundamentada na ideia de que essa relação viabiliza o uso de diferentes estratégias. As estratégias são delimitadas a partir das especificidades dos componente curriculares e dos conteúdos trabalhados. É interessante perceber que tanto em uma área quanto em outra a dimensão subjetiva e pessoal que envolve a relação professor-aluno parece definir a atuação docente.

Nesse indicador, é possível perceber que a convergência acontece no sentido de que as estratégias utilizadas estão assentadas na relação entre teoria e prática, ou seja, vão se constituindo à medida que os docentes vão desenvolvendo suas práticas.

Observa-se que sujeitos são de áreas distintas e, do mesmo modo, preocupam-se em considerar os saberes e também as dúvidas dos estudantes. O zelo dos professores pelo processo de aprendizagem aparece melhor em narrativas de professores de anos finais de carreira. Nesse contexto, destacamos o papel do professor gerativo, que ressignifica sua motivação para a escolha da profissão a cada prática bem-sucedida ao longo do seu percurso vital (MACIEL, 2009).

e) Dificuldades encontradas na docência.

Linguística, Letras e Artes (LLA): os PAI mencionaram a dificuldade de trabalhar a teoria e a prática de forma articulada, a falta de tempo para realização de outras tarefas como as que envolvem a pesquisa, as dificuldades na gestão do tempo para a sua formação continuada e a falta de base de um curso de licenciatura. Mostram dificuldades em relação às estratégias de aprendizagem, apresentando a necessidade de uma formação continuada em Pedagogia Universitária. Somam-se outras dificuldades como: falta de recursos, cisão entre ensino e pesquisa, carga de trabalho, turmas grandes e questões de infraestrutura, como espaço físico. Os PAT destacaram dificuldades em relação à imaturidade, à falta de estudo e de autonomia dos alunos e a problemas de infraestrutura; também faltam que o excesso de carga horária e de trabalho interfere na qualidade do trabalho docente, além da falta de experiência docente na área específica (em relação a colegas licenciados que não tiveram experiências 
docentes anteriores à entrada no ensino universitário). Os PAF destacam que os alunos não têm clareza sobre a área de formação na qual estão inseridos e falam sobre as precárias condições da infraestrutura (corpo docente, materiais e ferramentas de ensino, excesso de alunos, organização dos cursos - licenciatura/bacharelado).

Ciências Humanas $(\mathrm{CH})$ : para os PAI, as dificuldades estão relacionadas à dificuldade de trabalhar teoria e prática de forma articulada e à falta de tempo para realização de outras tarefas, como pesquisa; eles apresentam dificuldades na gestão do tempo para a sua formação continuada e criticam a falta de base dos alunos que ingressam nos cursos de licenciatura. Esses professores também relatam dificuldades em relação às estratégias de aprendizagem, apresentando a necessidade de uma formação continuada em Pedagogia Universitária. Compõem a gama de dificuldades: falta de recursos, dificuldade de conciliar o ensino e a pesquisa, carga de trabalho, turmas grandes, espaço físico restrito e falta de infraestrutura. Os PAT destacam dificuldades em relação à imaturidade, à falta de estudo e de autonomia dos alunos e a problemas de infraestrutura; também faltam do excesso de carga horária e de trabalho que interfere na qualidade do trabalho docente, além da falta de experiência docente na área específica (em relação a colegas (licenciados) que chegam e nunca deram aula antes). Por fim, os PAF relatam que apresentam dificuldades para estabelecer diálogo com outras áreas (produção do conhecimento), questões curriculares dos cursos e carga horária, compreensão de que no início da carreira a insegurança na docência está presente, falta de tempo (para trabalhar a ideia da natureza do conhecimento, para planejar e exercer a docência), por fim, a desvalorização do docente. As dificuldades apresentam-se como preocupações relacionadas ao trabalho docente em sala de aula.

As dificuldades envolvidas na docência também se constituem convergentes, pois os sujeitos de ambas as áreas as evidenciam no contexto da formação de novos profissionais e em relação a si próprios como profissionais.

\section{CONSIDERAÇÕES (IN)CONCLUSIVAS}

Considerando a análise realizada neste trabalho, visando investigar as influências das áreas específicas de conhecimento dos professores de uma IES pública nos movimentos da docência universitária e discutir potenciais indicadores que caracterizam a Pedagogia Universitária das licenciaturas nas áreas de Ciências Humanas e Linguística, Letras e Artes, a partir das narrativas de professores formadores, é possível afirmar que as licenciaturas possuem aspectos convergentes e divergentes que evidenciam características da formação de professores. 
Assim, no que diz respeito ao primeiro eixo e elementos descritos, sinalizamos que há convergência em relação à definição da área específica do conhecimento, uma vez que os professores definem suas áreas relacionando-a à pós-graduação, área de formação inicial e componente curriculares que ministram. Em relação aos conhecimentos básicos da área, observamos que a especificidade da área do conhecimento parece estar mais evidente para os sujeitos da área de LLA, pois estes compreendem o conhecimento pedagógico como complementação, enquanto os sujeitos da área $\mathrm{CH}$ entendem que a articulação com o conhecimento pedagógico é necessária e inerente à atividade docente. As relações conceituais parecem mais evidentes nas falas dos sujeitos da área de LLA do que em sujeitos da área $\mathrm{CH}$; nestes há evidências de que percebem apenas as inter-relações com as áreas afins. Entretanto, os sujeitos de ambas as áreas percebem a necessidade dessas inter-relações.

Destacamos que o tempo de carreira parece influenciar a compreensão que os professores têm a respeito da definição e dos conhecimentos básicos da área específica, bem como das relações entre esses conceitos e áreas afins, implicando uma contínua e processual produção pedagógica que gera a concepção do próprio processo formativo. Nesse sentido, os movimentos da docência podem ser compreendidos a partir da ideia de que esses professores aprendem a docência ao passo que vão produzindo suas compreensões sobre a área específica. Assim, o que podemos evidenciar é que o conhecimento da área específica é o alicerce sobre o qual a Pedagogia Universitária está assentada (ISAIA; MACIEL, 2013).

No que diz respeito ao recorte de análise que nos propomos neste artigo, vale ressaltar que os docentes são professores formadores de cursos de licenciatura, em que a tônica precisa estar sobre os processos de ensinar e aprender. Nessa direção, no segundo eixo buscamos explorar a relação entre compreender o conhecimento específico suficientemente para si e ser capaz de reorganizá-lo, facilitando a compreensão dos estudantes.

A partir dos indicadores que compõem esse eixo, podemos inferir que as áreas específicas parecem não interferir significativamente na compreensão e diferenciação do conhecimento específico e saber acadêmico. Destacamos que os sujeitos de ambas as áreas compreendem o conhecimento específico como teoria e o saber acadêmico como prático e parecem desenvolver essa consciência ao longo de suas carreiras, enfatizando a necessidade de uma dimensão prática aos conhecimentos trabalhados. Por meio da análise das narrativas é possível identificar que a articulação entre os níveis de conhecimento está mais evidente em LLA, uma vez que reconhecem que a trama entre os níveis de conhecimento é papel do formador. Evidenciamos que nas 
narrativas dos professores $\mathrm{CH}$, há compreensão da necessidade da articulação, no entanto os professores parecem compreender que tal responsabilidade deve ser compartilhada com os estudantes.

Nesse sentido, podemos perceber que são divergentes os níveis de compreensão sobre a diferenciação e articulação dos conhecimentos decorrentes de uma área específica entre os professores formadores, em nível superior. Tal constatação endossa a ideia de que o ato de ensinar é uma atividade complexa que requer a compreensão da área específica no que diz respeito aos conteúdos e saberes que deles decorrem, mas também a significação destes no contexto social (ALMEIDA; PIMENTA, 2011). Assim, está implicada a ideia de organização curricular, planejamento, estudo do campo de investigação dessa área e a produção de pesquisa, compreensão dos objetivos e propósitos desses conhecimentos para a formação de futuros profissionais, bem como aspectos pessoais e institucionais.

Ressaltamos que a compreensão e a adequação dos conhecimentos específicos ao contexto educacional se torna um elemento de extrema relevância no contexto da formação inicial de professores, considerando que os futuros professores deverão, a partir dessa noção, readequar tais conhecimentos para o contexto escolar. Considerando que as áreas de LLA e CH compreendem cursos de licenciatura, destacamos que, para além do estudo e compreensão da especificidade do conhecimento decorrente de determinado campo científico, é preciso apropriar-se de saberes próprios à profissão docente. Assim, o estudante do curso de licenciatura precisa desenvolver a capacidade de adequar, problematizar e transformar sua própria compreensão da matéria para que ela possa ser ensinada em outro contexto educativo, o da educação básica.

Sobre o terceiro eixo, observa-se que os docentes em anos iniciais de carreira se preocupam mais com questões pedagógicas, e professores mais experientes preocupam-se com questões mais abrangentes da profissão. Portanto, o terceiro eixo nos mostrou que as concepções dos professores acerca do modo como organizam o processo formativo para a compreensão dos estudantes está em relação dialógica com suas concepções quanto à sua área de conhecimento específico e à formação docente. Nossas análises evidenciaram a influência ainda muito forte do paradigma educacional tradicional de organização didática dos conteúdos, bem como nos processos avaliativos. Nestes prevalecem ainda a lógica do conhecimento acabado a ser reproduzido nas avaliações, não havendo abertura para os estudantes buscarem os saberes. Destacamos, nesse contexto, a necessidade de incorporar na formação dos professores o desejo pelo conhecimento, para que busquem e construam significados entre os conhecimentos. 
A formação docente nas licenciaturas demanda transformações. Nessa conjuntura, enfatizamos a necessidade de reverter a configuração formativa dos professores; entretanto, sabemos das dificuldades para essa mudança, pois a superação da dinâmica atual de formação é um obstáculo para os sujeitos que vivenciaram essa lógica em seu processo formativo ao longo da vida. Nessa direção, também consideramos a necessidade de superação de discursos, aparentemente atualizados e bem fundamentados, mas que acabam por não balizar, na prática, as estratégias adotadas. Sobre esse aspecto, questionamos a possibilidade do desenvolvimento de um processo de formação voltado à autonomia profissional e ao protagonismo docente.

Assim, concluímos este trabalho afirmando que pedagogias específicas podem se configurar para a formação de professores, pois a profissão docente precisa que sejam desenvolvidas estratégias formativas próprias. A atividade profissional do professor difere das demais profissões, e esses aspectos precisam ser tratados e vivenciados nos cursos de formação a fim de preparar melhor os docentes para a realidade profissional.

\section{REFERÊNCIAS}

ALMEIDA, M. I. de; PIMENTA, S. G. A construção da pedagogia universitária no âmbito da universidade de São Paulo. In: PIMENTA, S. G.; ALMEIDA, M. I. de (Org.). Pedagogia Universitária: caminhos para a formação de professores. 1. ed. São Paulo: Cortez, 2011. p. 19-43.

BOLZAN, D. P. V. Verbetes. In: MOROSINI, M. (Ed.). Enciclopédia de Pedagogia Universitária. 1. ed. Brasília, DF: INEP, 2006. p. 351-437.

BOLZAN, D. P. V.; ISAIA, S. M. de A. Pedagogia Universitária e Aprendizagem Docente: relações e novos sentidos da professoralidade. Revista Diálogo Educacional, Curitiba, v. 10, n. 29, p. 13-26, jan./abr. 2010. Disponível em: <http://www2.pucpr.br/reol/pb/index.php/dialogo?dd99=issue \&dd0=228>. Acesso em: 26. jul. 2016.

CONNELLY, M.; CLANDININ, J. Relatos de experiencia e investigación narrativa. In: LARROSA, J. et al. (Org.). Déjame que te cuente: ensayos sobre narrativa y educación. Tradução María Romanillos y Jorge Larrosa. 1. ed. Barcelona: Alertes, 1995. p. 11-59.

CUNHA, M. I. da. A educação superior e o campo da pedagogia universitária: legitimidades e desafios. In: ISAIA, S. M. de A.; BOLZAN, D. P. V. (Org.). Pedagogia Universitária e desenvolvimento profissional docente. 1. ed. Porto Alegre: EDIPUCRS, 2009. p. 349-374. 
CUNHA, M. I. da. A educação superior e o campo da pedagogia universitária: legitimidades e desafios. In: CUNHA, M. I. da (Org.). Trajetórias e lugares de formação da docência universitária: da perspectiva individual ao espaço institucional. 1. ed. Araraquara: Junqueira \& Marin; Brasília, DF, 2010. p. 59-81.

CUNHA, M. I. da. Verbetes. In: MOROSINI, M. (Ed.). Enciclopédia de Pedagogia Universitária. 1. ed. Brasília, DF: INEP, 2006. p. 351-437.

FRANCO, M. E. D. P.; KRAHE, E. D. Desenvolvimento profissional e Pedagogia Universitária em distintas áreas de conhecimento: novos tempos e novas tendências. In: FRANCO, M. E. D. P.; KRAHE, E. D. (Org.). Pedagogia universitária e áreas de conhecimento. 1. ed. Porto Alegre: EDIPUCRS, 2007. p. 27-37.

ISAIA, S. M. de A.; MACIEL, A. M. da R. Pedagogia Universitária: construções possíveis nas diferentes áreas de conhecimento. In: REUNIÃO NACIONAL DA ANPED, 36., 2013, Goiânia. Anais... Goiás: Anped, 2013. v. 1.

MACIEL, A. M. da R. A geratividade docente na educação do superior e os movimentos transformativos para o desenvolvimento profissional. In: ISAIA, S. M. de A.; BOLZAN, D. P.V. (Org.). Pedagogia Universitária e desenvolvimento professional docente. 1. ed. Porto Alegre: EDIPUCRS, 2009. p. 281-298.

MCEWAN, H. Las narrativas en el estudio de la docencia. In: MCEWAN, H.; EGAN, K. (Org.). La narrativa en la enseñanza, el aprendizaje y la investigación. 1. ed. Tradução Ofelia Castillo. Buenos Aires: Amorrortu, 1998. p. 236-259.

MORAES, R.; GALIAZZI, M. do C. Análise textual discursiva. Ijuí: Ed. Unijuí, 2007.

SCREMIN, G. Tecido Complexo Formativo Docente: repercussões das áreas nos processos formativos das licenciaturas. Tese (Doutorado em Educação)-Universidade Federal de Santa Maria, Santa Maria, 2014.

STAHL, L. Licenciatura em Espanhol: repercussões do conhecimento específico nos processos formativos docentes. Dissertação (Mestrado em Educação)-Universidade Federal de Santa Maria, Santa Maria, 2013.

Recebido em: 31 de julho de 2016 Aceito em: 08 de novembro de 2016

Endereço para correspondência: Cidade Universitária, Camobi, 97119-900, Santa Maria, Rio Grande do Sul, Brasil; greicescremin@gmail.com 